\title{
Paroxysmal nocturnal haemoglobinuria with renal, infective and immunological abnormalities
}

\author{
R. J. BOTELHO \\ M.B. B.S. \\ R. SAINSBURY \\ M.B. Ch.B.(N.Z.)
}

\author{
S. B. J. EBRAHIM \\ M.R.C.P., M.R.C.G.P.
}

M. J. BENDALL

B.Sc., M.B. B.S., M.R.C.P.(U.K.) Department of Health Care of the Elderly, Sherwood Hospital,
Hucknall Road, Nottingham NG5 IPD

\begin{abstract}
Summary
An elderly woman presented with paroxysmal nocturnal haemoglobinuria complicated by renal failure which was almost completely reversible. The illness was further complicated by a transient cerebral ischaemic attack and a chest infection with septicaemia due to Pseudomonas aeruginosa from which she died.

\section{Introduction}

Paroxysmal nocturnal haemoglobinuria (PNH) is a rare disease characterized by a membrane abnormality of red cells leading to episodic haemolysis. It has only occasionally been observed in the elderly (Sirchia and Lewis, 1975). The rarity of the disease, the insidious development of symptoms and variety of presentations mean that diagnosis may be incorrect or delayed (Polli et al., 1973).

PNH is associated with an increased incidence of infection particularly of the renal tract (Sirchia and Lewis, 1975). Renal impairment in PNH is usually
\end{abstract}

attributed to chronic pyelonephritis. However reversible acute renal failure in $\mathrm{PNH}$ has beelp reported and intense haemoglobinuria was though? to be the cause (Rubin, 1971).

A case is described of a woman who firs reported symptoms at the age of 85 years and who subsequently developed renal failure which was almost completely reversible. She had evidence on infective and thrombotic complications associared. with this disease and showed an immunologisabo abnormality not previously associated with PNH홍

\section{Case history}

An 87-year-old woman presented in Novembe 1980 with an 8-day history of malaise and inter: mittent vomiting with some diarrhoea which ha\& settled with kaolin and morphine mixture. She also had a 3-day history of dark brown strong-smelling urine. In December 1978 she had been seen at ar urology out-patients clinic with a 3-month history? of the intermittent passage of dark urine. This was

TABLE 1. Initial laboratory results

\begin{tabular}{|c|c|c|}
\hline & December 1978 & November 1980 \\
\hline $\begin{array}{l}\text { Haematology } \\
\text { Hb }(\mathrm{g} / \mathrm{dl}) \\
\text { MCV (fl) } \\
\text { WBC }\left(\times 10^{9} / \mathrm{l}\right) \\
\text { Platelets } \\
\text { ESR mm/hr }\end{array}$ & $\begin{array}{l}9 \cdot 5 \\
108 \\
8 \cdot 2 \\
\text { Normal } \\
84\end{array}$ & $\begin{array}{l}6 \cdot 1 \\
103 \\
\quad 9 \cdot 4 \\
\text { Normal } \\
117\end{array}$ \\
\hline $\begin{array}{l}\text { Biochemistry } \\
\text { Urea (mmol/l) } \\
\text { Creatinine }(\mu \mathrm{mol} / \mathrm{l}) \\
\text { Bilirubin }(\mu \mathrm{mol} / \mathrm{l})\end{array}$ & $\begin{array}{c}8 \cdot 3 \\
117 \\
24\end{array}$ & $\begin{array}{l}68 \cdot 7 \\
860 \\
74 \text { (85 conjugated) }\end{array}$ \\
\hline Urine & $\begin{array}{l}\text { Urobilinogen }++ \\
\text { Urobilirubin }+\end{array}$ & $\begin{array}{l}\text { Blood (positive Stix test) but no red } \\
\text { cell casts } \\
\text { Urobilinogen }+++ \\
\text { Urobilirubin }++ \\
\text { Haemosiderin positive }\end{array}$ \\
\hline
\end{tabular}


associated with malaise and jaundice which resolved (laboratory results, Table 1). An IVP was normal and cystoscopy showed a reddened bladder wall but was otherwise unremarkable. She was discharged from the clinic with no diagnosis.

Examination revealed yellow sclerae and mild dehydration. Pulse rate was $90 / \mathrm{min}$, BP $125 / 65$ $\mathrm{mmHg}$. There was no evidence of cardiac failure. There was tenderness in the right hypochondrium but no splenomegaly, hepatomegaly or lymphadenopathy. The remainder of the examination was unremarkable.

Initial investigations are shown in Table 1 together with corresponding findings in December 1978. The presence of urobilinogen, urobilirubin, haemosiderin and a positive test for blood in the urine together with her previous history of dark urine indicated a presumptive diagnosis of PNH.

Further laboratory investigations showed serum haptoglobin 0.05 g/l (normal 0.3-2.0 g/l) reticulocyte count $13.5 \%$, Ham's test strongly positive, antinuclear antibody positive. Serum DNA binding $68 \%$. Serum complement levels normal. Neutrophil alkaline phosphatase score 1 (very low). Escherichia coli urinary infection.

The patient remained oliguric despite i.v. rehydration and in view of her previous good health was commenced on peritoneal dialysis. This was maintained for 4 days during which time the blood urea fell from $72.2 \mathrm{mmol} / 1$ to $26 \cdot 3 \mathrm{mmol} / 1$. Blood urea and creatinine both fell further with continuing rehydration.

In addition to dialysis and rehydration, she was given a course of ampicillin $500 \mathrm{mg} 4$ times daily for the urinary infection and was transfused with $4 \mathrm{u}$. of dextran sedimented washed concentrated red cells.

Following treatment of her renal failure, urinary infection and anaemia, she initially made good progress and had nearly regained independence. On 19th November 1980 she suffered a transient left hemiparesis which resolved completely within $24 \mathrm{hr}$.

On 24th November 1980 she developed a temperature, a cough productive of yellow sputum and clinical signs of a chest infection. She was started on amoxycillin. Chest X-ray showed consolidation at the left lung base with cavitation. A sputum culture and blood cultures grew Pseudomonas aeruginosa. Treatment with tobramycin was commenced but her condition deteriorated and she died on 2nd December 1980.

Post-mortem examination showed suppurative bronchopneumonia with lung abscesses. Both kidneys were small with thinning of the cortex with scarring consistent with recurrent infection. There was also evidence of brownish iron staining of the renal parenchyma. Her brain was not examined.

\section{Discussion}

Paroxysmal nocturnal haemoglobinuria presents most commonly between the third and fifth decades with an equal sex distribution (Beal, 1974). It is only exceptionally seen over the age of 70 years (Sirchia and Lewis, 1975). This patient's diagnosis was probably not made on her first presentation in December 1978 because the findings were attributed to haematuria rather than haemoglobinuria. There is often delay in making the diagnosis and the initial diagnosis is often incorrect (Polli et al., 1973).

A case of paroxysmal nocturnal haemoglobinuria with reversible renal failure has been previously reported (Rubin, 1971). In that case the post-mortem findings were of acute pyelonephritis without evidence of chronic renal disease and the renal failure was attributed to haemoglobinuria. Acute renal failure due to haemoglobinuria is also well recognized following haemolytic transfusion reactions in the absence of chronic renal disease. However, the chronic renal failure of PNH is most frequently associated with recurrent pyelonephritis. Intense deposition of haemosiderin in renal tubular cells is found in all patients with PNH coming to post-mortem whether or not renal failure was present during life (Crosby, 1953). The reversible component of the renal failure in the present patient suggests that the urinary tract infection may have precipitated haemolysis which further compromised her renal function.

Thrombosis is one of the major complications of PNH, and this patient's transient right hemiparesis may be attributable to the hyper-coagulable state associated with PNH. The cause of this hypercoagulable state is unclear but there are 3 factors which may contribute: abnormal platelets found in the disease; intravascular lysis of abnormal erythrocytes; and an increased activity of clotting factors (Dacie, 1967).

PNH is associated with an increased incidence of infection and this patient's illness terminated with a $P$. aeruginosa septicaemia and bronchopneumonia. Apart from the renal tract the bronchopulmonary tree is the most frequent site of infection. Increased susceptibility to infection in PNH may be due to neutropenia but impaired qualitative function of neutrophils has also been implicated (Sirchia and Lewis, 1975). Saturation of the reticulo-endothelial system as a result of haemolysis has also been invoked as a factor in the susceptibility to infection in haemolytic disorders (Kaye and Hook, 1963).

The final point of interest was the finding of a positive antinuclear antibody with high DNA binding. These findings are usually associated with systemic lupus erythematosus of which there was no corroborative clinical evidence in this case. The authors are unaware of any previously described 
association of PNH with these immunological findings.

\section{Acknowledgment}

We are grateful to Mrs W. Goh for her typing of the manuscript.

\section{References}

BeAL, R.W. (1974) Paroxysmal nocturnal haemoglobinuria. Medical Journal of Australia, 2, 741.

Crosby, W.H. (1953) PNH. Relation of clinical manifestations to underlying pathogenic mechanisms. Blood, 8, 769.
DACIE, S.V. (1967) The Haemolytic Anaemias: Congenita and Acquired. Part IV. Churchill, London.

KAYE, D. \& Hook, E.V. (1963) The influence of hemolysis or blood loss on susceptibility to infection. Journal offs Immunology, 91, 65.

Polli, E., Sirchia, G., Ferrone, S., Meruriali, F. \& ZANella, A. (1973) Emoglobinuria Parossistica Notturna Revisione Critica. Edizioni Cilag-Chemie Italiana, Milano

Rubin, H. (1971) Paroxysmal nocturnal hemoglobinuria with renal failure. Journal of the American Medicad Association, 215, 433.

SirchiA, G. \& Lewis, S.M. (1975) Paroxysmal nocturna $\vec{P}$ haemoglobinuria. Clinics in Haematology, 4, 199. 